\section{Mouths of waders}

Feeding and the Feeding Apparatus in Waders: A Study of Anatomy and Adaptations in the Charadrii. By P. J. K. Burton. Pp. 150. (British Museum (Natural History): London, 1974.) $£ 3.50$.

Dirivg recent decades workers may have been somewhat deterred from studying the Charadriiformes by the documentation provided in "Witherby" and by the detailed knowledge possessed by amateur ornithologists but there is now evidence of a widespread resurgence of interest. This present book, a quite admirable discussion of functional morphology, considers charadrioid bill structure and oral musculature from a variety of viewpoints.

The information on overt feeding behaviour which is contained in the opening sections includes many original observations alongside a useful panoramic survey culled from the world literature. I was particularly interested in the statements about Pluvialis squatarola as they contrast with the data obtained by Dr G. A. Parker and myself. The remainder of the book deals in detail with the degrees of rhynchokinesis, and the variations in bill, tongue and hyoid structure, which are associated with different methods of feeding. In particular Dr Burton emphasises that highly rhynchokinetic upper jaws have probably evolved independently in at least seven lines of Charadrioidea. The interdependence of modifications for a particular method of feeding is certainly widely known but this account provides many further examples.

Written with great clarity, the book will be a valuable addition to specialist libraries and encourage a continuing synthesis of morphology and ethology. One can only express passing regret that, although the work was initially supported by the Scientific Research in Schools Committee of the Royal Society, the author gave up his teaching post to complete it. Surely this was not the intention hehind the committee? Britain needs able and enthusiastic teachers.

Ronald Pearson

\section{Seabed skeletons}

Recent Sedimentary Carbonates. Part 1: Marine Carbonates. By J. D. Milliman Pp. $x v+375+39$ plates. (Springer-Verlag: Berlin and New York, 1974.) DM66; \$27.10.

THis book is an excellent attempt to synthesise present knowledge about calcium carbonate in the marine environment, its composition, sedimentation and diagenesis. It is apparent that Milliman has used his experience gained in researches over a broad spectrum of the field of Recent sediments and also a wealth of data from the latest literature to put together this comprehensive textbook, which will appeal to final year undergraduates, research students and established carbonate sedimentologists.

The book is divided into four parts: introduction, carbonate components, marine carbonate sedimentation and carbonate diagenesis. Part 1 includes a valuable introduction to the techniques employed in the analysis of such parameters as texture, petrography, mineralogy and elemental and stable isotope composition. This practical aspect is supplemented by the two appendices. which, although very brief, do establish a starting point for the identification, in thin section and under reflected light, of the major carbonate components of Recent marine sediments. The major portion (part 2) of the book synthesises an extensive literature on the ecology, calcification, petrography and composition of various skeletal and nonskeletal carbonate components. This section includes many quantitative data on topics including growth rates, mincralogies, minor trace element and stable isotope distributions which will serve as a useful reference for marine sedimentologists. The third part of the book deals with the distribution of marine carbonates. Milliman does not concentrate on a few shallow tropical sea environments, which is sensible, for this particular setting is treated in considerable depth in other recent books. but instead he gives equal attention to the shallow seas, shelf waters and the deep sea. The final part traces the diagenetic alteration of carbonates within the marine environment through degradation, cementation and dolomitisation.

The style is clear and the presentation straightforward. One of the most useful and original features of the book is the plentiful tabulation of quantitative and descriptive data from a wide variety of sources. In this way such information as chemical composition of skeletons, distribution of major planktonic foraminifera species, and depositional environments and chemical properties of modern marine dolomites are succinctly expressed for easy comparison and assimilation. The photographs are arranged in plates which on the whole are clear and appropriate, though for ease of reading I would have preferred photographs interspersed with the text. Several photographs are too small to serve much value and the general standard of plates is not the excellent quality one has come to expect from Springer-Verlag geological publications.

It is inevitable that this book will be compared with the recent comprehensive texthook on carbonate sediments and their diagenesis by Bathurst.
Though the themes of the two books are similar the contents overlap to a relatively small degree (as an indication only 375 references are common to the two books which have a total of over 2,000 references). This partly results from the different experiences and approaches of the two authors and partly from the inclusion in Milliman's book of many references to works published during the past three years.

T. P. Scoffin

\section{Explaining solid state}

Electronic Properties of Crystalline Solids: An Introduction to Fundamentals. By Richard H. Bube. Pp. xiii +524 . (Academic: New York and London, January 1974.) $\$ 35 ; £ 16.80$.

THF solid state physics contained in this book is, at first sight, fairly traditional, hoth as regards subject matter and treatment. On closer examination, however, it becomes apparent that Dr Bube has made a useful and significant addition to the range of text books now available to third year undergraduate and first year postgraduate students specialising in solid state physics. The author clearly intended to explain the main elements of the subject within a sound mathematical framework. He wisely resisted the temptation to discuss many aspects superficially and instead concentrated on taking a few examples of solid state phenomenon and treating them in some depth. Reviewers who judge a book by what has been left out may, therefore, find the choice of material not to their liking; I, for example, would like to have seen a little more on metallic alloys. But these are matters for personal judgment and should not be allowed to detract from a well written and beautifully produced textbook.

There are twelve chapters in the book which cover the three principal themes of solid state physics. The first threc chapters focus attention on wave theory and the application of quantum mechanics to simple systems. The examples here were carefully chosen with an eye to later chapters. The next three chapters develop the hand theory of solids taking as a starting point the free electron (Hartree) model. The reader will, if he works through these chapters and the excellent range of problems associated with each of them, gain a good understanding of basic band theory. I was particularly pleased to see a discussion of 'bands' versus 'bonds' and that the concept of electronegativity is at last appearing in solid state physics textbooks. The role of localised energy levels leading to the characteristic behaviour of semiconductors is described, a shade too briefly perhaps, in chapter 9. The remainder of the 